\title{
Presencias y ausencias del padre durante el proceso de enfermedad y recuperación de su hijo: un estudio de caso
}

\author{
Presences and absences of the father during the process of \\ illness and recovery of his child: a case study
}

\author{
Montserrat Soriano Chavero* \\ María Alejandra Salguero Velázquez**
}

\begin{abstract}
Resumen
El objetivo de la presente investigación fue analizar las presencias y ausencias que vive un padre joven durante el proceso de enfermedad y recuperación de un hijo. Integrando una investigación cualitativa en su tradición de estudio de caso, se llevaron a cabo entrevistas semiestructuradas. Los resultados muestran que la enfermedad de un hijo es un evento que somete a altos niveles de estrés y cansancio a las parejas. Construyendo presencias relacionadas al cuidado de los hijos, pero ausencias en torno a la relación de pareja, pues existen dificultades para negociar tiempos, economía y cambios 0 transformaciones en los roles y dinámica familiar. En México son escasas las políticas públicas que fomenten la participación de los hombres en el cuidado de sus hijos enfermos, lo que se refleja en la poca capacidad de las instituciones de Salud Pública para incluirlos como parte del núcleo familiar.
\end{abstract}

Palabras clave: paternidad, enfermedad, hijos, ausencia, presencia

\begin{abstract}
The objective of this investigation was to analyze the presences and absences that a young father lives during the process of illness and recovery of a child. Integrating qualitative research into their case study tradition, semi-structured interviews were conducted. The results show that the illness of a child is an event that subjects couples to

\footnotetext{
* Licenciada en Psicología y Doctorante de Psicología Social y Ambiental por la Universidad Nacional Autónoma de México, Facultad de Estudios Superiores Iztacala.

** Doctora en Sociología, Maestra en modificación de conducta y Licenciada en Psicología por la UNAM. Profesora de Tiempo completo en la Facultad de Estudios Superiores Iztacala. Universidad Nacional Autónoma de México. Integrante del Sistema Nacional de Investigadores, CONACYT.
} 
Revista Punto Género N. 13. Junio de 2020

ISSN 0719-0417 / $131-149$

high levels of stress and fatigue, building presences related to childcare, but absences around the relationship, as there are difficulties to negotiate times, economy and changes or transformations in family roles and dynamics. In Mexico there are few public policies that encourage the participation of men in the care of their sick children, which is reflected in the low capacity of Health Institutions to include them as fathers.

Keywords: paternity, disease, children, absence, presence

Fecha de recepción: Julio 2019

Fecha de aprobación: Julio 2020

\section{Introducción}

Desde el construccionismo social, la perspectiva de género y la psicología sociocultural, la paternidad es entendida como una construcción social que modifica la vida de las personas, como una forma de ser y estar en el mundo atravesada por el género. Una manera de ser hombre es también una forma de ser padre, mediada, aprendida y reproducida a través de prácticas sociales que hacen referencia a diversas funciones de cuidado, protección, proveeduría y responsabilidad para con los hijos e hijas. Están fuertemente relacionadas a factores sociales, culturales, históricos y políticos, así como la trayectoria y el momento del ciclo de vida donde se encuentren padres y descendientes (Salguero, Córdoba y Sapién, 2007).

En la actualidad, hay una amplia diversidad de estructuras y dinámicas familiares que ejercen y entienden la paternidad de múltiples formas. Por ejemplo, ante la conformación de una familia, se puede ser un padre presente o ausente en la crianza y el cuidado, ya que es durante el proceso de hacer familia y devenir padre que los varones aprenden a priorizar el tiempo en las relaciones con su pareja, hijas e hijos, buscando proveer, pero también implicarse afectivamente (Salguero y Marco, 2014; Lupica 2016).

De manera que un aspecto importante en el proceso de construcción de los individuos serán siempre las pautas de relación, donde padres, hijos e hijas, son vistos como aquellas personas que se aman y procuran estar juntos y presentes o discuten y se separan, están unidos o distanciados y se muestran presentes o ausentes (Jiménez, 2011:80). Siendo primordial situar el carácter relacional bajo el cual se construyen tanto la presencia como la ausencia, pues más que una condición patológica de la ausencia paterna, se pueden concebir ambas como parte de procesos de socialización familiar, donde las prácticas culturales y dinámicas familiares posibilitan o entorpecen la conciliación de arreglos, negociaciones y transformaciones de prácticas relacionadas con los roles de género que atraviesan las funciones de madres y padres en el hogar.

Al considerar la perspectiva relacional de género durante el momento en el que las personas hacen familia, veremos que los varones siguen colocando su participación en la proveeduría económica, protección, seguridad, disciplina y compañía en los juegos con los hijos, pero mostrando carencias afectivas hacia ellos (Kaufman, 1999). Aunque de 
acuerdo con Salguero, Córdoba y Sapién (2007), ser responsable, proveedor y representante de la familia hace que los varones asuman una postura de protección para atender las necesidades económicas, pero también emocionales de los hijos e hijas. Esta construcción de significados como padre se lleva a cabo mediante procesos de socialización con sus hijos y pareja, pues es con quien finalmente se acuerda de manera conjunta un proyecto de vida en familia, donde además de las funciones proveedoras del padre, se espera que den lugar a interacciones lúdicas y de afecto hacia hijos e hijas.

La imagen del padre tradicional autoritario y distante se ha venido cambiando por la de un padre más involucrado en la crianza de los hijos y con posibilidades de expresar emociones y sentimientos, la cual se ha promovido desde hace más de 50 años (Scavino y Batthyány, 2019). Particularmente desde los años 70 para Latinoamérica (Lupica,2009), como parte del diseño de políticas públicas y programas orientados a involucrar de manera activa a los varones en el cuidado de sus hijos, partiendo de la premisa de que la presencia de un padre, sea biológico o no, que no sea violento y esté involucrado en el cuidado y crianza, es positiva para la niñez, la familia, las mujeres y para ellos mismos (Barker y Verani, 2008).

Las nuevas formas de interacción de los varones que son padres están caracterizadas por el tiempo que compartan con sus hijos e hijas, la accesibilidad que tiene el niño o la niña para interactuar con su padre y la responsabilidad que ejerce en torno a su educación. Lamentablemente, el discurso social no siempre va de la mano con su participación y actuación dentro de estas prácticas en su vida cotidiana. Fuller (2000) menciona que las paternidades no responden a un único modelo, sino que, en distintas etapas de la vida de los varones, su sexualidad, el trabajo y la pareja, tienen distintos significados. Por ejemplo, Castro (2004) indica que la mayoría de los varones aceptan y valoran ser sensibles, afectivos y tiernos, reconociendo su parte de responsabilidad en los vínculos sobre todo con su pareja, hasta que transitan por la edad adulta o que han alcanzado lo básico en sus objetivos laborales. Durante las primeras etapas de su vida, los hombres se enfocan casi exclusivamente al ámbito público, al trabajo y la proveeduría, por lo que su atención y dedicación a los vínculos afectivos está delimitada principalmente a la relación de pareja, siendo un soporte emocional, social y material en la realización de sus proyectos tanto familiares como profesionales al cubrir con las tareas de cuidado y atención a la otra y el otro.

Si bien es cierto que las actividades en torno al cuidado de los niños y las niñas continúan estando sesgadas por el género, otorgando un mayor peso y sobrecarga a las mujeres (Lupica, 2013), hay indicios de nuevas formas de ejercer la paternidad, pero estas suceden en contextos donde las instituciones, particularmente las del mercado laboral, reproducen lógicas que aplazan la división sexual del trabajo para las mujeres y no preponderan el modelo de hombre proveedor único, posibilitando paternidades más reflexivas desarrolladas por parejas que en la vida cotidiana negocian y reflexionan la importancia que tiene para ambos la provisión económica del hogar y sus proyectos de vida laborales y personales (Scavino y Batthyány, 2019). 
Revista Punto Género N. 13. Junio de 2020

ISSN 0719-0417 / $131-149$

\section{Construyendo presencias o ausencias cuando los hijos se enferman}

Un aspecto preponderante en el desarrollo de la presente investigación fue el cuestionamiento sobre la manera en la cual se construyen las formas de presencia o ausencia de los padres cuando los hijos e hijas se enferman, debido a que la condición y dinámica familiar cambia por completo, de ahí que se incorporara como un ejercicio reflexivo y de indagación.

\subsection{Negociación en pareja}

La información documental señala que la negociación en pareja se vuelve fundamental para la construcción de una paternidad más presente en aspectos relacionados con el cuidado y la crianza, pues ante la enfermedad de un hijo o hija, la familia debe adoptar nuevas dinámicas y arreglos que les permitan enfrentar de manera efectiva dicha situación.

Una de las principales necesidades a las que hay que hacer frente, corresponde a las actividades y horarios de cuidado destinados al paciente enfermo, pero con frecuencia la responsabilidad de decidir la atención, el tratamiento y la adherencia al mismo, recae en un miembro femenino de la familia. De acuerdo con Pérez Orozco (2006), Carrasco (2011) y Rodríguez (2015) dentro de esta sociedad con una organización fuertemente androcéntrica y ampliamente desigual, el trabajo de cuidado, incluyendo el que se le brinda a las personas enfermas, ha estado histórica y socialmente asignado a las mujeres, pues es socializado e interiorizado como su deber dentro de las familias mientras se invisibiliza para el mercado y la economía. De esta forma las mujeres son vistas esencialmente como cuidadoras aún y cuando perciban un ingreso por otra actividad que sea remunerada en el mercado laboral. En cambio, los varones podrán seguir desempeñándose en el ámbito de lo público, sacando tiempo de sus jornadas laborales para cuidar de los hijos en tanto no descuiden su función primordial de proveeduría económica.

\subsection{Responsabilidad y cuidado de un hijo enfermo}

Si bien el cuidado hacia las personas enfermas está mediado por una situación de dependencia ampliamente desigual (Pérez Orozco, 2006), la condición de enfermedad en un miembro de la familia puede llevar a modificar los roles y tareas asignadas tradicionalmente dentro del hogar a mujeres y varones, siempre y cuando la experiencia de la enfermedad implique una crisis que los lleve a reestructurar sus significados y creencias en torno a las formas de convivencia legitimadas anteriormente, requiriendo revalorar nuevamente la importancia del evento, así como la postura que cada miembro de la familia asumirá en torno a sus responsabilidades y tareas de cuidado.

En este sentido, Grau y Espada (2011) mencionan que la enfermedad de un hijo es un evento que producirá cambios en la distribución de las tareas en el hogar, en la comunicación entre la pareja, la manera en la que cada uno de ellos reacciona ante la situación de la enfermedad, las relaciones sexuales, la crianza de los otros hijos en caso 
de que los hubiese, las relaciones con la familia extensa y la comunidad en general. Requiriendo principalmente de una constante negociación y mejora de las relaciones socio-afectivas en pareja que les permita afrontar dichos cambios.

La intensidad de estos cambios dependerá de varios factores, principalmente de la gravedad de la enfermedad, sobre todo si ésta requiere o no de hospitalización, porque dicha condición produce una fuerte ruptura en la dinámica familiar, debido a la distribución de horarios para cuidar de la persona enferma, aprenderse el funcionamiento de los hospitales para realizar los trámites administrativos, así como el impacto emocional que implica ser hospitalizado (Grau y Fernández, 2010).

Es común que la hospitalización de un hijo o hija requiera modificaciones en el estilo de vida familiar, pues implica la reorganización de roles que permitan tener más tiempo para turnarse y hacerle compañía debido a la imposibilidad de planificar la vida familiar, social y profesional a corto plazo, produciéndose un aislamiento social y la interrupción de la mayoría de las actividades recreativas de la familia (Grau y Espada, 2011). Con frecuencia los progenitores mencionan una preocupación por descuidar al cónyuge y al mismo tiempo ver menos al hijo enfermo, llevándolos a esforzarse por armonizar los tiempos de cuidado para con los hijos, pero también para cubrir sus propias necesidades, siendo importante adaptarse a esta nueva situación que llevará a decidir quién asumirá el cuidado principal de la persona enferma, ocasionando conflictos, que tienden a mantener emociones de angustia, bloqueo afectivo, pérdida de esperanza por tener un hijo enfermo, o conductas obsesivas respecto al control de la enfermedad (Salvado, Hernández, Roca, Almeda, Méndez y García, 2014).

Independientemente de quien sea la cuidadora o el cuidador principal, esta persona debe tener períodos de descanso y ser capacitado o capacitada para poder superar las situaciones de crisis que implique su función, lo que podría explicar por qué las madres son quienes utilizan más técnicas de afrontamiento que los padres, pues se dedican mayor tiempo a cuidar de otros y otras, siendo los varones quienes presentan más síntomas de bourn out que los progenitores de niños sanos, dañando también su estabilidad física y emocional (Salvado, Hernández, et. al, 2014)

En este sentido, Gavin y Wysocki (2006) encuentran que una mayor participación del padre en el cuidado de la enfermedad de los hijos se asocia a un mejor funcionamiento psicológico materno y marital además de una mejor adhesión al tratamiento del niño. Pero esto depende claramente de la dinámica previa que exista en la pareja, pues si bien en algunos casos la enfermedad de un hijo puede unir más a los padres al aumentar el aprecio y la confianza mutua como parte de enfrentar una situación difícil en equipo, también exacerba los conflictos previos a la enfermedad (Castillo y Chesla, 2003).

\subsection{Conflictos ante las formas de abordar una situación de enfermedad}

Grau y Espada (2011:127) mencionan que las causas de algunos conflictos en este proceso se pueden dividir en cuatro aspectos: el primero tiene que ver con la carga 
desproporcionada en el cuidado del niño y el intento de un cónyuge por ausentarse del hogar, dando pie a sentimientos como el rencor, que llevan al divorcio. La segunda causa es la falta de comprensión emocional entre los cónyuges, por ejemplo, si la madre se siente apática y es incapaz de hacerle frente a la situación mientras el marido se vuelve poco comprensivo y se enfada, insistiéndole que se sobreponga a la situación, generando más problemas. La tercera hace referencia a las discrepancias en cuanto al trato hacia hijos e hijas. La cuarta a las discrepancias que existen sobre la noción de "normalidad" en la familia, pues muchas parejas tienen dudas sobre si deben continuar llevando una vida normal, debido a que sienten remordimiento cuando piensan en salir y divertirse, considerando que no tienen derecho a hacerlo ante la enfermedad de su hijo o por temor a dejarlo solo. Esto, porque si bien después de la hospitalización la familia adapta a la vida cotidiana las exigencias de la enfermedad, hay familias que, aunque se adaptaron al período de hospitalización, se desintegran y entran en crisis cuando el enfermo es dado de alta.

Como en todo proceso que lleva intempestivamente a modificar la trayectoria de vida, la enfermedad de un hijo requiere de redes de apoyo para brindarle el cuidado necesario, siendo la familia extensa el principal recurso con el que cuentan las parejas. Son los abuelos y abuelas quienes, a pesar de reaccionar con incredulidad, culpabilidad y tristeza ante la enfermedad del nieto o nieta, se vuelven una gran ayuda como cuidadores de los otros hijos o hijas e incluso llegan a tomar decisiones respecto al tratamiento o modificaciones en la familia a raíz de la enfermedad (Castillo y Chesla, 2003).

Es importante considerar que las transformaciones que afectan el mercado laboral pueden frustrar proyectos 0 bien disolver aquellos que se han construido en pareja (Castro, 2004), sobre todo en condiciones de vulnerabilidad como es vivir la enfermedad de un hijo o hija. Si bien la condición socioeconómica es importante al momento de tratar de romper las resistencias que implica abandonar el modelo tradicional de madre cuidadora y padre proveedor, es importante tomar en cuenta que existe una necesidad de generar políticas que consideren la manera en la que internalizamos y encarnamos el género desde nuestros mismos cuerpos a través de las prácticas sociales en la vida cotidiana (Connell, 1995/2015), si se pretende que exista una distribución más equitativa en las tareas de cuidado entre hombres y mujeres.

\subsection{Organización social del cuidado y políticas públicas}

Particularmente en México, falta un amplio camino por recorrer en materia de políticas públicas que aseguren la tarea del cuidado de toda la familia, pues aunque existe una amplia variedad de servicios públicos de cuidado, gran parte de ellos se siguen proporcionando mediante actividades no remuneradas ofrecidas al interior de los hogares. En el $71 \%$ de los casos por mujeres, lo que fomenta las condiciones de subcontratación laboral y la economía informal, siendo necesario impulsar políticas públicas que hagan efectivo el reconocimiento de que recibir o dar cuidado, es un derecho inherente a todos los miembros de la famililla (Villa, 2019). Se debe considerar que las actividades de cuidado no son responsabilidad única de la familia, sino del Estado, las empresas, los 
organismos sin fines de lucro y las sociedades, constituyendo así una red de organización social del cuidado (Esquivel, Faur y Jelin, 2012).

El concepto de organización social del cuidado de acuerdo con Lupica (2013) es el arreglo que surge del cruce entre las instituciones que regulan y proveen servicios de cuidados a las personas y los modos como los hogares de distintos niveles socioeconómicos y sus miembros se benefician de ellos. Esto supone prestar atención a los aspectos micro sociales, pero también al rol de la política social en la provisión y regulación de las relaciones, actividades y responsabilidades de cuidado asignadas a distintas instituciones y sujetos.

La ideología del Estado-Nación en México supone que hay una promesa de Bienestar, producto de la urbanización e industrialización pos revolucionaria, donde se les permita a las personas, sobre todo a las más jóvenes, superarse social e intelectualmente para ser "hombres de bien" que pueden mantener una familia (Salguero, Córdoba y Sapién, 2007). Aunque hay cambios en cuestión de política pública en México respecto al papel de los hombres como cuidadores, por ejemplo, la regulación de las licencias por paternidad, el derecho a tener acceso a estancias infantiles o la posibilidad de elegir estar presente en el parto de los hijos, hace falta un giro en materia de derecho laboral que permita regular otros permisos por paternidad para la mayoría de los trabajadores del sector público que reciben seguridad social.

Si bien en el 2019 se modificó la ley federal del trabajo y la ley de seguridad social con base en los preceptos $4^{\circ}$ y $5^{\circ}$ de la Constitución Política de los Estados Unidos Mexicanos encargados de velar el interés superior de la niñez, la protección a la salud y el acceso a un trabajo digno, para garantizar el acceso de licencia de trabajo por enfermedad a padres de niños con cáncer, la reforma quedó inconclusa en varios aspectos. El primero de ellos es su limitación a padres o tutores legales con hijos no mayores a 16 años, a pesar de que la ley del seguro social protege a los hijos de los trabajadores no mayores a 25 años, siempre y cuando sigan dentro del Sistema Nacional Educativo, y que la misma reforma ya implica una carga económica para los patrones cuando excede los 28 días, pues tendrán que pagar completamente las contribuciones, siendo una motivación para sustituir al empleado que se encuentre en estas condiciones, fomentando desigualdades sociales (Idc online, 2019).

En este sentido, como indican Scavino y Batthyány (2019), las políticas de inclusión laboral que contribuyan a garantizar el ejercicio de la paternidad para los varones implican pensar en las condiciones sociales y de vulnerabilidad de los mismos, ya que sectores económicos más pobres ni siquiera tendrán acceso a servicios de salud pública, al tener vínculos informales con el mercado laboral. Así, se verán imposibilitados para hacer frente a situaciones que signifiquen un desajuste en la dinámica familiar y la implicación en el cuidado, sobre todo en condiciones aún más vulnerables, como lo es la enfermedad de un hijo o hija.

Algo fundamental en el proceso de enfermedad y recuperación es la participación de los servicios de profesionales de la salud, pues como menciona Grau y Espada (2011: 129) es indispensable reunir información adecuada para evaluar el grado de resiliencia y 
vulnerabilidad que presentan las familias, con la finalidad de poder ayudarlos a enfrentar el impacto emocional de un diagnóstico de enfermedad que los lleva a reorganizar sus vidas, para poder adaptarse a las exigencias de los tratamientos que en particular se requieran, sin que esto desencadene formas de interacción entre las parejas y las familias que construyan ausencias y se vivan y signifiquen como abandono o pérdidas. Sobre todo en el caso de los varones, que en su papel de padres casi siempre han sido considerados como participantes periféricos en el cuidado de sus hijos e hijas, porque su rol principal es la proveeduría.

Por ello, situándonos bajo una estructura socioeconómica y política donde las personas nos desarrollamos y en la que existe una organización genéricamente binaria y ampliamente desigual en los trabajos de cuidado, el objetivo de la presente investigación es analizar las presencias y ausencias que vive un padre joven durante el proceso de enfermedad y recuperación de un hijo.

\section{Metodología del estudio.}

Se presenta una investigación de corte cualitativo en su tradición de estudio de caso que explora un fenómeno o proceso a través del tiempo, mediante la recolección de información detallada y a profundidad de datos, incorporando un paradigma interpretativo, considerado como la mejor opción para analizar los significados de presencia y ausencia que vive un padre durante el proceso de enfermedad y recuperación de un hijo. De acuerdo con Ito y Vargas (2005) el paradigma comprensivo/interpretativo, asume que el conocimiento se obtiene por medio del dialogo entre sujetos representantes y portadores de una cultura dentro de un tiempo y espacio determinado con la finalidad de conocer su punto de vista en ciertos fenómenos específicos, así como el sentido que estos le atribuyen a sus acciones. Además de que la investigación cualitativa tiene la característica de incluir sensibilidad crítica e interpretativa (Denzin y Lincoln, 2011), que permite representar mediante los diálogos del participante la propiedad relacional que tienen la construcción de significados de presencia y ausencia paterna como parte de requerimientos familiares insertos en un orden de género desigual.

\subsection{Participante y procedimiento.}

Se presenta el caso del padre de un niño ${ }^{1}$, que desde su nacimiento enfrenta diversos padecimientos de salud: respiratorios, digestivos, de piel y constantes alergias que lo mantuvieron durante tres años en hospitales, motivo por el cual su padre se adentró totalmente en su cuidado, dejando de lado durante ese periodo de tiempo su relación de pareja y su propia salud, para tratar de mantener no solo su presencia en la relación con su hijo en los hospitales, sino también la estabilidad económica hasta su

\footnotetext{
${ }^{1}$ Este artículo se deriva del corpus de datos obtenidos de un proyecto más amplio financiado por la Universidad Nacional Autónoma de México, DGAPA PAPIIT denominado: "Paternidad en los varones: presencias y ausencias" IN305817, que retoma las experiencias de hombres mexicanos en torno a su participación como padres en diversas condiciones, que los llevan a construir presencias o ausencias dentro la familia con los hijos y la pareja.
} 
recuperación. Por motivos éticos de confidencialidad en la investigación (Gonzales, 2002), se solicitó el consentimiento informado, haciendo explicito que sus nombres y datos personales serían cambiados por otros, asignándole el nombre de Eduardo, para referirnos a su caso.

Utilizando la técnica bola de nieve se contactó a un hombre que fuera o hubiera sido padre de un niño con alguna condición de enfermedad, acercándonos a través de conocidos a un participante con estas características. Se realizó el proceso de negociación para que accediera a participar en la investigación y pudiésemos llevar a cabo las entrevistas para acercarnos a la construcción dialógica en el encuentro e identificar el sentido de su experiencia como padre, ante la situación vivida con su hijo en condición de enfermedad, el proceso de construcción o reconstrucción de la situación familiar y particularmente la relación de pareja. Se llevaron a cabo tres entrevistas semiestructuradas en profundidad que posibilitaron guiar el encuentro con el participante durante el proceso de reconstrucción de la experiencia.

La estrategia analítica empleada fue el análisis de contenido categorial para metodología cualitativa que, de acuerdo con Krippendorff (2002), permite formular inferencias identificando de manera sistemática y objetiva características específicas dentro de un texto, haciendo referencia al contenido bajo el cual se construyen y desarrollan los significados, permitiendo tener un panorama general de la entrevista, además de la reconstrucción de los discursos de los participantes. Se identificaron categorías de análisis a partir del marco teórico de referencia y los ejes elaborados para dar cuenta de la experiencia: 1) presencias y 2) ausencias.

\section{Resultados}

A continuación, se presentan las categorías de presencia y ausencia de acuerdo a los discursos señalados por el participante:

\subsection{Presencias. Involucramiento y cuidados paternos}

La presencia de Eduardo como padre durante el proceso de enfermedad y recuperación de su hijo corresponde al período de recopilación de la información en los años 2010 al 2013 y se da desde el momento en el que la pareja presenta los primeros síntomas del parto, brindándole contención emocional, sabiendo que era un nacimiento prematuro y así lo narra:

"El nacimiento de mi hijo fue muy interesante, el 25 de marzo de 2010 a las 3 de la madrugada agarra, se despierta ella tranquilamente y dice, 'voy al baño', regresa del baño, me dice 'idespiértate!', 'estoy despierto', y me dice 'ies que estoy tirando mucha agua', le digo, '¿cómo que estas tirando mucha agua?, 'isí!, estoy tirando mucha agua', veo y le digo, 'no te preocupes, ya vamos a ser papás', o sea yo sabía que era prematuro, pero al final estuve muy tranquilo, le digo, 'no te preocupes ya vamos a ser papás, vámonos al hospital'". 
Debido a que era un nacimiento prematuro con complicaciones en el parto había un alto riesgo de que el bebé o la madre murieran; momentos que Eduardo narra con desagrado y preocupación, pues también estaba presente la posibilidad de no poder tener más hijos. Es relevante como narró todo el proceso mediante el cual se mantiene expectante ante el nacimiento del niño, proporcionando datos como la hora de nacimiento, lo que le plantean los médicos respecto a las problemáticas del mismo y la estancia de su hijo en la incubadora. Sitio donde la mayoría de los padres mexicanos podían ver a sus hijos e hijas recién nacidos cuando un parto tenía lugar en un hospital público hasta antes del 2019, año en el que la secretaría de salud de México declara una reforma a la ley de salud materna-infantil, para que todas las mujeres puedan estar acompañadas por un familiar o su pareja en la sala de parto. Históricamente, los varones habían sido mantenidos en la periferia durante todo el proceso de embarazo y nacimiento de sus hijos cuando éstos tenían lugar en un hospital público, donde comúnmente se les impedía el acceso a la sala de alumbramiento, y así lo narró como quien vive la espera desde afuera:

"Llegó al hospital y literalmente la detuvieron, nosotros esperábamos un parto natural, pero fue cesárea porque el niño venía con el cordón en el cuello y pues hubo que sacarlo... sentí horrible, yo con esa ilusión y ganas de ser papá, pero también de ser esposo, y el problema es que me decían 'si se queda ella, es probable que ya no pueda tener hijos'. Para eso dan las 4:30 de la tarde y todavía no sacaban al niño porque se hacía todo el procedimiento ahí o se trasladaba a otro hospital, o sea, ya por la especialidad que requería; y pues decidieron hacer el procedimiento ahí. Cuando dijeron, 'nació un niño a las 4:50 de la tarde, están bien, están en recuperación los dos' me sentí tranquilo, él estuvo en incubadora un rato y no pasó de ahí".

Lamentablemente, comienzan a presentarse complicaciones en la salud del hijo que llevan a Eduardo a modificar completamente su estilo de vida:

"Después de que nació mi hijo tuvimos un periodo de cierto descanso, pero finalmente tuve que meterme a los hospitales mucho tiempo, porque tuvo varios problemas de respiración, con el píloro, alergias, le cambiaron hasta la sangre varias veces, entonces, conocí los hospitales, cómo se movían los hospitales, estudiaba en los hospitales, vivía ya en los hospitales. Es que salía y entraba, literalmente estaba 15, 20 días, salía y al día siguiente ya estábamos de nuevo en el hospital, o sea, ya cuando creíamos que ya se había controlado todo, algo más surgía, primero era que el niño no podía respirar, iya maduró!, 'vamos a la casa, vamos a dormir', ahora el niño vomita otro tiempo, hasta le iban a hacer la bendita cirugía, nos dijeron, '¿cirugía o tratamiento?, el tratamiento va a ser más tardado', ivamos al tratamiento!, ya, sale de eso y ahora el niño tiene alergias, alergias que lo llevaban al hospital porque te dicen 'dele leche', le das leche, y el niño ahora sí parece; le digo a mi hijo, 'parecías perro a medio morir ', '¿cómo?', 'si parecías perro rabioso' y pues vas de nuevo al hospital"'. 
Revista Punto Género N. 13. Junio de 2020

ISSN 0719-0417 / $131-149$

En ese periodo del proceso de enfermedad del hijo, la función de proveeduría de Eduardo se vuelve fundamental, pues es la manera de hacerse presente en el cuidado con el hijo, aunque eso lo lleve a asumir deudas:

"Íbamos a consulta externa a muchos hospitales, en sí lo que hacía era buscar tener todas sus citas en una sola semana, para que esa semana fuera solo semana médica y yo dedicarme a lo demás. La cosa es que, pues, ahora necesitaba conseguir dinero para ponerme a pagar todos los préstamos, porque no fueron prestamos bajos y lo que me pagaban en las consultorías no me alcanzaba para pagar el préstamo ni hacer lo demás, entonces me dediqué a juntar, juntar y terminar de pagar y eso me llevó mucho tiempo".

Implicarse en la salud de su hijo lo lleva a involucrarse en los cuidados referentes a su alimentación, desde prepararle de comer, hasta pensar de qué manera hacerle la comida y los lugares donde poder comprar sus alimentos con la finalidad de mejorar sus alergias y brindarle salud:

"El alergólogo decía 'no puede comer esto', entonces fue cuando entendí que había Chedraui premier, que Wal-Mart tenía un apartado especial, cuando su mamá se va de la casa y se queda a vivir conmigo yo pongo la dieta y el niño empezó a dejar sus alergias, hasta que me lo dieron de alta. Empecé a meterle mucha verdura y el alergólogo me dice '¿qué le está haciendo a su hijo?', 'pues nada más le cambié la dieta, me puse a leer que cosas de una dieta estándar puede comer y es lo que preparo"'.

\section{Cuidando a mi hijo y descuidando mi salud}

Sin embargo, aunque aprende a cuidar de su hijo, Eduardo descuida su salud durante el proceso de enfermedad y recuperación de su hijo y así lo narra:

"Me volví adicto a todo lo que me mantuviera despierto. Yo no tomaba café, o sea literalmente la primera vez que tomé café fue en Chiapas, porque surgió un proyecto. Para que yo me pudiera concentrar todo el tiempo y terminarlo en una semana, estaba durmiendo una, dos horas al día, de tal forma que me dijeron 'tomate algo, porque no vas a aguantar, vas a desfallecer', entonces empecé con té, yo ni té tomaba, el té no me hizo, empecé a tomar café, pase al Red Bull, después del Red Bull pase al Monster, después combiné los dos, después a cosas más fuertes porque necesitaba estar despierto, entonces el que se volvió adicto en ese tiempo fui yo".

\section{La exigencia de la proveeduría}

La proveeduría sigue siendo fundamental en la construcción de identidad como padre presente de Eduardo, sin embargo, este proceso de enfermedad y recuperación de su hijo también lo ha llevado actualmente a revalorar el tiempo que convive con su familia y así lo narra: 
Revista Punto Género N. 13. Junio de 2020

ISSN 0719-0417 / $131-149$

"En el instituto [donde trabajaba el participante] hay chance de apoyarte; uno de los investigadores me dijo, 'podemos apoyar con una chamba, la vas a hacer desde casa, pero todo es estadística, ¿sabes estadística?', 'no, no sé estadística, pero dame tres días'y fue así como fui aprendiendo, porque tenía muy buena memoria, entonces si yo me digo 'ya me voy a centrar a trabajar para ganar dinero 'sé que lo voy a lograr, la onda es que también es involucrarme mucho tiempo y desapartarme de los niños mucho tiempo, y no, yo procuro dedicarle mi tiempo a los mugrosos [sus hijos]".

\subsection{Ausencias}

Aunque Eduardo va construyendo presencia como padre en la relación con su hijo mediante la revaloración de su papel como proveedor y cuidador, al mismo tiempo va construyendo ausencias en la relación de pareja que los llevan a la separación.

Estas ausencias se van construyendo en dos aspectos, el primero tiene que ver con la ausencia física y el deterioro en la relación y así lo narra:

"Estábamos cansadísimos y no lo vivimos juntos. Los hospitales públicos te dicen 'solo puede estar una persona para acompañar al niño, sale la persona, le entregan su pase y ya entra la siguiente persona'. Literalmente los primeros dos años después del nacimiento de mi hijo, nos vimos más que en los inter de cambio, el trato fue 'tú lo cuidas de día yo lo cuido de noche', escogía la noche porque así tenía la posibilidad de, saliendo, hacer alguna actividad que nos diera recursos, ya que los primeros meses mis ahorros se fueron. Y se fueron porque nos dijeron 'en tal hospital particular tienen la posibilidad de atender a su hijo', y pues si tuvieron la posibilidad de tratar a mi hijo de ciertas cosas, pero todo lo demás, pues ya no, ya no me alcanzaba, entonces regresamos a los pediátricos del D.F, y fue esa asignación de 24 × 24, el chiste fue de que no nos vimos [él y su pareja]".

"No nos daba ni tiempo de pelear, no nos daba tiempo de nada, literalmente un día le dije a mi mamá, 'mamá necesito un paro, que se vaya una noche al hospital a cuidar al Ibra [su hijo enfermo]', dice 'hijo ¿que no tienen quién?', le dije '¡no!, inecesito dormir con mi esposa aunque sea una vez, hágame el paro!', literalmente nos vimos mi esposa y yo y nada más nos dormimos, o sea, porque estábamos cansadísimos, fue un tiempo de mucho cansancio, yo llegué a bajar como 10 kilos, si ahorita peso 72, pesaba 56 kilos en ese entonces y ya tenía más o menos esta estatura.

El segundo tiene que ver con el castigo por no cumplir con los ideales o mandato social, debido a la incapacidad de la pareja para afrontar el estrés por la enfermedad del hijo, en la que tampoco se mantuvieron los acuerdos que llevarían la transición hacia nuevos modelos de ser padre, incluyendo el apoyo de la pareja como proveedora para resolver los problemas económicos que presentaron y así lo expresa: 
Revista Punto Género N. 13. Junio de 2020

ISSN 0719-0417 / $131-149$

"Algo que afectó mucho es que ella dejó de trabajar, a la hora de que nos dicen 'su hijo requiere todo esto', le dije de la manera más políticamente correcta 'tenemos que buscar baro, no va a ser barato, jvamos!, ¿tú tienes la posibilidad de que con tu trabajo nos den un servicio médico y tener aparte para todo esto?', 'no pues no, ¿tú tienes la posibilidad de conseguirlo?', 'yo tengo la posibilidad de conseguir consultorías y meterme a tres cuatro en un solo momento y nos va a dar para pagar', y me dice 'pues tú te vas a trabajar y yo me quedo', el problema es que ella dice 'yo me quedo', creyendo que era sencillo quedarse. Un día en el hospital regresamos de urgencia y el niño... pues literalmente se desvaneció, dejó de respirar y ella estaba con él, les empezó a gritar a los médicos, a las enfermeras y demás, empezó a hacer un drama que lo comprendo, porque al final es tu hijo. La corrieron del hospital, 'lámale, ponen el número de contacto, llámale al papá', ahí tiene que ir el papá, entonces ahora yo me tenía que aventar los dos turnos durante un tiempo, o sea no era tan sencillo, ella dejó de trabajar, y después eso nos genera bronca porque no teníamos los dos ingresos, teníamos solo mi ingreso, pero más del $80 \%$ del ingreso se iba en el niño".

"Ella ya no quiso regresar a trabajar, su primer pretexto es, 'ya estoy desactualizada, son dos años', le digo '¿y luego?', 'es que, pues tendría que tomar un curso de capacitación', 'te pago el curso', y le pagué el curso, 'jay no!, es que ya me di cuenta que mi carrera no me gusta, es muy tediosa, hay no', le digo, 'oye, si no te gusta tu carrera estúdiate otra, tú eras buena en la prepa para todo lo que era grecolatinas, estudia etimologías', 'sí, sí me gustaría', hizo el examen y lo reprobó por un acierto y eso me la frustró más".

Al no ver la posibilidad de participación de su pareja para cubrir los gastos económicos, los miembros de la familia extensa se vuelven una red de apoyo, como lo señalan (Castillo y Chesla, 2003), para el participante al momento de enfrentar la situación económica precaria, producto de los gastos realizados para sostener la recuperación de su hijo cuando ésta se volvió insostenible y así lo cuenta:

"Después de esos dos años como que ya no fue lo mismo, porque también tenía que estar cuidando a mi hijo y demás, en sí de tan mal que estaba la situación económica, mi papá y mi mamá me dijeron 'sabes qué, tenemos un espacio en Chimalhuacán', era un terreno, 'tienes la posibilidad de construir aunque sea un algo para que ya no pagues renta, puedes ocupar ese espacio, hazlo' y fue así como llegamos a vivir a Chimalhuacán, o sea, porque literalmente ya no me alcanzaba para pagar la renta, literalmente era pagar la renta, pagar los servicios, yo solito ya no la veía llegar".

Finalmente, Eduardo relata que el peso de la proveeduría y la falta de acuerdos en torno al tiempo que se le tenía que dedicar al cuidado del niño, así como las constantes demandas de su pareja por ausentarse del hogar (Grau y Espada, 2011) van generando distanciamientos y ausencias que culminan en divorcio:

"Tuve que sacar préstamos bancarios para solventar los gastos de mi hijo. No compramos ropa, el celular era el mismo, nuestra alimentación cambió para 
comprar los medicamentos y ella empezó a compararse con sus amigas 'es que mis amigas si pueden', 'pueden porque no tienen un hijo enfermo, no seas así, se hace lo que se puede"'

"yo estaba con ellos, pero literalmente, su mamá en ese entonces me decía 'quiero salir con mis amigas, pero no puede ir el niño', 'pues vete tú, yo lo cuido', 'pero es que no voy a llegar', y si llegué a decirle, 'sabes qué, sí tú ya no quieres estar conmigo y si solo vamos a estar por el niño, mejor dímelo así o sea, y nos divorciamos, y esto lo podemos hacer, cada quien su vida, pero no nada más vamos a estar por el niño' y era algo que para mí no se me hacia sencillo pero era la opción más viable".

Lo que muestran los discursos del participante en torno a su experiencia vivida durante el proceso de enfermedad de su hijo, fue un grado de involucramiento constante tanto en tiempo como en las actividades que requería el proceso de hospitalización y cuidado, sin descuidar la función que históricamente se le ha atribuido a los varones respecto a la proveeduría como parte esencial en el proceso de formar una familia y ser responsables de ella.

Asumir como hombre y padre el cuidado y responsabilidad de su hijo durante el proceso de enfermedad, hospitalización, cuidado y recuperación le lleva a construir una presencia constante. Sin embargo, la falta de acuerdos y negociación con la pareja, les lleva a asumir formas distintas de implicación, donde ella deja por completo la responsabilidad económica en manos de él, como histórica y socialmente ha formado parte de las funciones del ser hombre y padre. No obstante, se convierte en una condición de desigualdad social, pues aun teniendo la posibilidad de involucrarse en alguna actividad laboral que le permitiera contribuir con la proveeduría compartida, sobre todo en las condiciones que estaban viviendo con su hijo enfermo, le deja a él por completo dicha responsabilidad, colocando en una situación de vulnerabilidad no solo la relación de pareja, sino la condición de salud de él como padre, ya que como menciona, asumía poco cuidado de su salud, pues no tenía posibilidad de dormir ni descansar, descuidando incluso su alimentación, al asumir el cumplimiento de la proveeduría mediante de la aceptación de diversos trabajos de asesoría a costa de su salud.

Aspectos que ponen el punto de reflexión no solo en las condiciones individuales sino socialmente construidas con la pareja. Finalmente no es sólo lo que le pasa a un hombre cuyo hijo se encuentra enfermo y que como padre decide involucrarse y estar presente durante todo el proceso, sino que desde las instituciones laborales no es considerado, pues simplemente es un hombre que se ausenta del trabajo, las razones que presenta en términos de la enfermedad de su hijo es algo secundario, ya que quienes se tendrían que encargar del cuidado, de acuerdo a este orden social androcéntrico, serían las mujeres, por la visión feminizada del cuidado, lo cual se convierte en una condición de desventaja social. En México no contamos con políticas públicas que consideren la participación de los varones en el ámbito del hogar y la familia, sobre todo cuando los hijos se enferman o llegan a requerir procesos de hospitalización largos como es el caso de nuestro participante, alterando la relación y 
Revista Punto Género N. 13. Junio de 2020

ISSN 0719-0417 / $131-149$

dinámica familiar hasta la separación, como fue el caso del que damos cuenta y donde se construyen ausencias a partir de la normatividad social y de las formas de relación y participación de la pareja.

\section{Consideraciones Finales}

Las instituciones de Salud Pública en México presentan serias limitaciones para que los padres se involucren en el cuidado de los hijos enfermos, generando ausencias con su pareja al tomar la decisión de acompañar a su hijo en el proceso de enfermedad y recuperación, ya que no se permite la presencia de ambos progenitores. Otro inconveniente se relaciona con la falta de permisos por enfermedad de los hijos de parte del sector laboral, considerando que esa es una responsabilidad de las madres y no de los padres a quienes no se les visualiza como cuidadores.

En el caso de algunos hombres como nuestro participante, les lleva a buscar empleos de "freelance" para estar presente en el cuidado del hijo, pero con dificultades económicas que afectan la relación conyugal, siendo uno de los detonantes de la separación e incluso del divorcio. La enfermedad de un hijo recién nacido es un evento que somete a altos niveles de estrés y cansancio a las parejas jóvenes que nunca imaginan pasar por dicho proceso, llevándolos a negociar constantemente los tiempos, economía y dinámica familiar.

Al igual que en investigaciones realizadas por Grau y Fernández (2010), Grau y Espada (2011) y Salvado et. al. (2014), la relación de pareja se convierte indiscutiblemente en un espacio de aprendizaje y reflexión al momento de tratar de negociar distribuciones y prácticas equitativas de cuidado. Aunque se presenten conflictos, las parejas negociadoras podrán resolver las tensiones en torno a las responsabilidades de convivencia con los hijos, sin embargo en el caso del participante, la enfermedad del niño exacerba el desinterés por mantener una dinámica familiar que no permite la transición o modificación de los roles tradicionales de madre cuidadora, padre proveedor, trayendo en este caso una sobre carga de estrés para el padre, debido a la imposibilidad de cubrir al $100 \%$ con la proveeduría, por tratar también de mantenerse presente en la vida y las necesidades que requería la hospitalización del hijo.

Esta situación vuelve al cuestionamiento acerca de si la proveeduría es también una forma de hacerse presente en el cuidado hacia la familia y los hijos, pues en este proceso de enfermedad podemos ver que el participante significa la proveeduría como lo más importante en relación a mantener el bienestar de la salud de su hijo y la estabilidad familiar, incluso a costa de su propia salud, revalorando esta postura cuando se da la recuperación del niño y la separación y divorcio con su pareja, poniendo mayor peso al tiempo que convive con sus hijos como una forma de mantenerse presente en sus vidas.

Es importante que las políticas públicas generen mecanismos que, si bien fomenten la corresponsabilidad y la presencia de los varones en el cuidado, garanticen su derecho a disfrutar de la paternidad considerando las condiciones a las que están 
sometidos como parte de los "privilegios de ser hombre", que en condiciones de vulnerabilidad social entorpecen su salud y bienestar tanto personal como familiar.

La reflexión nos lleva a considerar que el ejercicio de la paternidad forma parte de un proceso relacional de género que se construye con la pareja, donde los acuerdos, la manera como se negocien los deseos, expectativas, formas de involucramiento y participación formen parte del ser pareja y familia. Esto tendría que llevarnos a replantear la manera como construimos en el día a día nuestras formas de participación como madres y padres en la relación con nuestros hijos.

Considerar que los procesos de salud o enfermedad de los hijos pueden ser una posibilidad de afrontar justamente el ser pareja, asumiendo el compromiso más allá de los estereotipos del ser mujer o ser hombre, de las responsabilidades asumidas, donde a los hombres les corresponde cumplir con la proveeduría aun cuando en ocasiones, aunque tengan más de uno o dos trabajos, no les alcance para cubrir con las necesidades económicas de la familia, y que incluso vaya de por medio su salud física y emocional. Habrá que deconstruir los modelos de género históricamente asignados y legitimados, para considerar su carácter relacional en los procesos de construcción para lograr una vida más digna, equitativa y responsable independientemente del género que se nos ha asignado; ver al otro u otra como alguien con quien construir la posibilidad de encuentro para poder sobrellevar la situación tan difícil a la que se enfrentan cuando alguno de sus hijos se encuentra en una condición de enfermedad, cuando requiere de hospitalización y donde la presencia, apoyo y responsabilidad mutua es absolutamente necesaria; no se puede dejar al otro sólo afrontando la difícil situación de su hijo y a su vez la responsabilidad de la proveeduría, la contención emocional y temporal con la pareja.

En ese sentido, hablar de presencias o ausencias desde una perspectiva relacional de género, asume el sentido de construcción con el otro. Ese otro relacional a través del cual se puede dar sentido a la vida, sea través de la presencia como en la historia de caso que presentamos, la presencia significa involucramiento con el hijo, cumplir con la proveeduría en condiciones difíciles por estar presente en la situación de hospitalización, llevándolo a construir ausencias con su pareja hasta llegar a la separación formal.

\section{Bibliografía}

Barker, Gary. \& Verani, Fabio (2008): La participación del hombre como padre en la región de Latinoamérica y el Caribe: Una revisión de la literatura critica con consideraciones para políticas. Brasil: Promundo - Save thechildren.

Berger, Peter \& Luckman, Thomas (1996): La construcción social de la realidad. Argentina: Amorrortu editores.

Carrasco, Cristina (2011): La economía del cuidado: planteamiento actual y desafíos pendientes, Revista de economía critica, No.11, p.205-225. 
Revista Punto Género N. 13. Junio de 2020

ISSN 0719-0417 / $131-149$

Castillo Edelmira \& Chesla, Catherine (2003): "Viviendo el cáncer de un(a) hijo(a)", Colomb Med, Vol.34, No.30, p.155-163.

Castro, Ines (2004): La pareja actual Transición y Cambios. Buenos Aires, Argentina: Lugar Editorial.

Connell, Raewyn (1995/2015): Masculinidades. Segunda Edición español, México: PUEG.

Denzin, Norman \& Lincoln, Yvonna (2011): "Introducción General. La investigación cualitativa como disciplina y como práctica", en N. Denzin y Y. Lincoln (Edis.): Manual de Investigación Cualitativa. El Campo de la investigación cualitativa (Vol. I), 43 -101. México: Gedisa Editorial.

Esquivel, Valeria., Faur Eleonor \& Jelin, Elizabeth (2012): Las lógicas del cuidado infantil. Entre las familias, el Estado y el mercado. Buenos Aires: Ides, UNFPA, Unicef.

Fuller, Norma (2000): Paternidades en América Latina. Lima, Perú: Fondo Editorial de la Pontificia Universidad Católica del Perú.

Gavin, Leslie \& Wysocki, Tim (2006): "Associations of parental involvement in disease management with management with maternal and family outcomes in families with children whit chronic illness", Journal pediaticr Psychology, Vol. 31, No. 5, p. 481-9.

Gonzales, Manuel (2002): "Aspectos éticos de la investigación cualitativa", Revista Iberoamericana de Educación, No.29, p. 85-103.

Grau Claudia \& Fernández María (2010): "Familia y enfermedad crónica pediátrica, Anales del Sistema Sanitario de Navarra, Vol.33, No.2, p. 203-12.

Grau, Claudia. \& Espada, María del Carmen (2011): "Percepciones de los padres de niños enfermos de cáncer sobre los cambios en las relaciones familiares",PSICOONCOLOGÍA, Vol.9, No.1, p. 125-136.

Idc online: Seguridad Social (2019): Licencia para padres con hijos diagnosticados con cáncer. Disponible en https://idconline.mx/seguridadsocial/2019/05/20/licencia-para-padres-con-hijos-diagnosticados-con-cancer

Ito, María \& Vargas, Blanca Inés (2005): Investigación Cualitativa para psicólogos. De la idea al reporte. México: FP-UNAM. Porrúa.

Jiménez, María Lucero (2011): "Ideas sobre las transformaciones en las paternidades en el contexto de cambios sociales y económicos", en: O. Hernández, A. García, y K. Contreras (Coord.), Masculinidades en el México contemporáneo, 77-88. México: Plaza y Valdés Editores. 
Revista Punto Género N. 13. Junio de 2020

ISSN 0719-0417 / $131-149$

Kaufman, Michael (1999): "Men, Feminism, and Men's Contradictory Experiences of Power" en: H. Brod, y M. Kaufman (Edis): Theorizing Masculinities, 59-83. Sage Publications, recuperado de: http://www.michaelkaufman.com/wp content/uploads/2009/01/men feminism.pdf

Krippendorff, Klaus (2002): Metodología de análisis de contenido. Teoría y práctica. Barcelona: Paidós.

Lupica, Carina (2009): La función paterna en la nueva dinámica familiar: de la provisión económica al compromiso emocional. Boletín de la maternidad pág. 2.

Lupica, Carina (2013): Trabajo decente y cuidado compartido: hacia una propuesta de parentalidad. Santiago de Chile: Organización Internacional del Trabajo-OIT y Programa de las Naciones Unidas para el Desarrollo-PNUD. Recuperado de: http://www. oitcinterfor.org/sites/default/files/file publicacion/113B09 86 span. $\underline{\mathrm{pdf}}$

Lupica, Carina (2016): "Licencias de paternidad y permisos parentales en América Latina y el Caribe. Herramientas indispensables para propiciar la mayor participación de los padres en el cuidado de los hijos e hijas", MCS-Masculinities and social change, Vol. 5 No.3, p. 295-320.

Pérez Orozco, Amaia (2006): Amenaza tormenta: La crisis de los cuidados y la reorganización del sistema económico, Revista de economía crítica, Vol. 5, p.7-37.

Rodríguez, Corina (2015): Economía feminista y economía del cuidado Aportes conceptuales para el estudio de la desigualdad. Aportes conceptuales para el estudio de la desigualdad, Nueva Sociedad, No. 256, p.30-44.

Salguero, Alejandra., Córdoba, Diana \& Sapién, Salvador. (2007): Reproducción y paternidad experiencias y aprendizajes de los hombres. México: FESI-UNAM.

Salguero, María Alejandra \& Marco, María (2014): "Reflexiones sobre sexualidad, reproducción y paternidad en estudiantes universitarios en México" Gazeta de Antropología, 2014, Vol.30, No.3, p. 1-13.

Salvado, María Cristina., Hernández, Eva., Roca, Montserrat., Almeda, Jesús., Méndez, Carmen \& García, Rosa María (2014): "Vivencias y proceso de adaptación a la enfermedad del padre y los hermanos de un niño con diabetes tipo: 1 revisión bibliográfica descriptiva". Nure Investigación. No 71, p. 1-9. 
Revista Punto Género N. 13. Junio de 2020

ISSN 0719-0417 / $131-149$

Scavino, Sol \& Batthyány, Karina (2019): "Caminos hacia la corresponsabilidad: los varones en el cuidado infantil en Uruguay", Cadernos Pagu, No.56, p.1-33.

Villa, Suheid (2019): Las políticas de cuidados en México. ¿Quién cuida y como se cuida? México: Friedrich-Ebert-Stiftung-México. 